\title{
Optimised operation of storage systems integrated with MV photovoltaic plants, considering the impact on the battery lifetime
}

\author{
S. Barsali, R. Giglioli, G. Lutzemberger*, D. Poli, G. Valenti \\ ${ }^{1}$ Department of Energy, Systems, Territory and Constructions Engineering, University of Pisa, \\ Largo Lucio Lazzarino n. 1, 56122, Pisa (Italy) \\ *Corresponding author: tel. +39050 2217311, \\ email: lutzemberger@dsea.unipi.it
}

\begin{abstract}
Nowadays, the energy storage technology is bringing new opportunities to the power systems, not only providing the electric grid with regulation, reserve and backup services, but also filling the gap between the timing of production and consumption. This enables price arbitrage techniques, aimed at maximising the economic revenue obtained by charging or discharging the storage, based on the time variation of electricity prices. This paper shows how to optimise the operation of a storage device in presence of a PV generating plant, possibly combined with a local load. An optimisation technique based on a dynamic programming tool implemented with the open source Modelica language is here proposed and tested on different case studies. In particular, different storage sizes and losses models have been considered, as well as the dependence of the storage lifetime on the depth of discharge of its operational cycles. Finally, a payback analysis calibrated on present and future cost scenarios is presented and discussed.
\end{abstract}

\section{Keywords}

Control strategy, Energy storage, Optimisation, Photovoltaic plant, Price arbitrage.

\section{Introduction}

The electric power system is facing important challenges associated with the integration of intermittent generation, mainly wind and solar energy plants. This fact, together with the need to manage large variations 
between peak and off-peak demand and to operate the system guaranteeing the security and quality of supply, is motivating TSOs (Transmission System Operators) and DSOs (Distribution System Operators) to investigate the contribution of new technologies, such as electrochemical energy storage, as a grid facility able to increase the hosting capacity of RES (Renewable Energy Sources) [1].

The mature and effective operation of storage devices within the power system is a complex task that involves technical, economic, commercial and regulatory arrangements. Anyway, the inclusion of storage in a power system increases control opportunities over the fundamental energy processes related to production, transport and use of electricity; in turn, storage creates new options about timing, location and source of energy conversion plants [2] [3] [4].

For these reasons, storage technology is also bringing new business opportunities to producers, consumers and to their combination (prosumers). Storage not only enables them to provide the electric grid with regulation, reserve and backup services [5] [6], but actually fills the gap between the timing of production and consumption. This gives concrete added value to price arbitrage techniques, the main scope of this paper, aimed to absorb electricity from the grid when price is low, and/or to sell it when price is high.

Cyclic differences between peaks and valleys of the electricity prices set by the spot markets are mainly related to the variability of energy amounts to be met by conventional thermoelectric power plants along the day. In the user's perspective, optimising the daily operation of the storage, i.e. setting its charge and discharge cycles, means exploiting such differences to the fullest; this is a critical task to make storage a cost-effective solution.

In the recent scientific literature, many approaches have been proposed to optimise the operation of a storage device in stand-alone configuration or in combination with a load [7]-[10] or a renewable power plant [11]-[18]. This paper is specifically devoted to the combination of a PV plant and an electrochemical storage device, with the possible presence of a local load.

A recent review of optimisation criteria of arbitrage techniques [19] clearly confirms that most of traditional approaches use a combination of Linear Programming (or Mixed-Integer Linear Programming, [20]) and RES/load forecasting tools. Nevertheless, methods like those proposed in [21] are not able to 
capture the nonlinearities associated to an accurate modelisation of storage losses. The latest literature is trying to overcome the limitations of linear programming; for example, [22] provides interesting forecasting models for PV generation, but is conceived in the perspective of a network operator, not in the one of the prosumer. For this reason, a simplified approach is used to optimise the storage operation, based more on sequential decision making rules than on a real daily optimisation. Other papers propose the use of dynamic programming [23]. For example, [24] is devoted to find a closed-form solution that however is not reached for any possible configuration of generation and load power profiles and requires a very complex mathematical formulation. Paper [25] suggests using general-purpose optimisation tools like CPLEX Studio, but the proposed algorithm simply maximises the self-consumption of photovoltaic energy, without exploiting the full potential of bidirectional energy exchanges between the PV plant, the load and the power network. Other authors, like in [26], focus their attention also on price forecasting techniques; nevertheless, it is worth remembering that the hourly prices of the following day are usually set sufficiently in advance by the day-ahead spot market; hence, they do not need to be forecasted for the purposes of storage optimisation.

In addition, the above mentioned literature does not appear to take sufficient account of the strict dependency of the storage lifetime on the kind of charge/discharge cycles. In fact, if maximising the arbitrage value of a storage device is always a complex task especially in the presence of both load and local generation, it becomes even more difficult when considering that storage lifetime strongly depends on the depth of discharge of cycles it is asked to follow. This means that optimizing its operation is not only about selecting charge and discharge timing, but also finding the best compromise between restraining the depth of discharge and shifting considerable energy amounts per day.

In order to take into account all the above mentioned aspects with a comprehensive and novel approach, in this paper we propose to use OpenModelica [27], and in particular, its dynamic programming tool JModelica [28], to optimise the daily operation of an electrochemical storage device combined to a PV plant, with or without a local load. From the analysis of the literature, it emerges that this tool was recently applied to power systems, but never for the optimal operation of electrochemical energy storage systems.

In fact, JModelica was used in the past to optimise the start-up operations of a combined-cycle power plant, with the aim to reduce thermo-mechanical stress on the outer surface of the steam turbine rotor [29]. In 
another case, JModelica was used to optimise the start-up operations of a steam power plant, in order to achieve a given steam pressure and temperature in a short period [30]. Then, also the optimal operation of a thermal storage in a Concentrated Solar Power plants has been analysed in [31] [32]. In this case, in the absence of storage, the operating point of the power plant needs to follow the variations of the solar radiation. On the contrary, when a thermal storage is introduced, it is possible to maintain constant power output during cloud passage, or to shift the production to better meet variable-price tariffs; this is obtained by optimally controlling the mass flow rate from the thermal storage to the steam generator.

Further than the novelty of the comprehensive approach and of the tool, in this paper particular attention has been devoted to describe and model the control architecture and to implement the optimisation procedure. A detailed model of electrochemical storage losses is explained and discussed for comparison with the usual approach of modelling a constant round-trip efficiency; the strict dependence of the optimal charge/discharge cycles on the proper modelisation of losses is widely discussed. Several case studies show the impact of the presence of a local load and of the storage size on the plant cost-effectiveness; the dependence of storage lifetime on the depth of discharge of its cycles is duly taken into account. The payback analysis is focused both on present storage costs and on their possible future decrease.

\section{The control architecture}

The main goal of the control architecture is to provide a general, flexible and effective strategy for the operation of the storage system, in order to optimize and control the power exchange between a RES (Renewable Energy Source) and the grid, with the possible presence of a local load.

The general structure, which is operating in a real plant [33], is depicted in Figure 1, where the industrial load can be included or not (visible in figure). As shown, different control functions have been implemented: the optimizer, the scheduler, the droop controls, and the storage state estimator. 


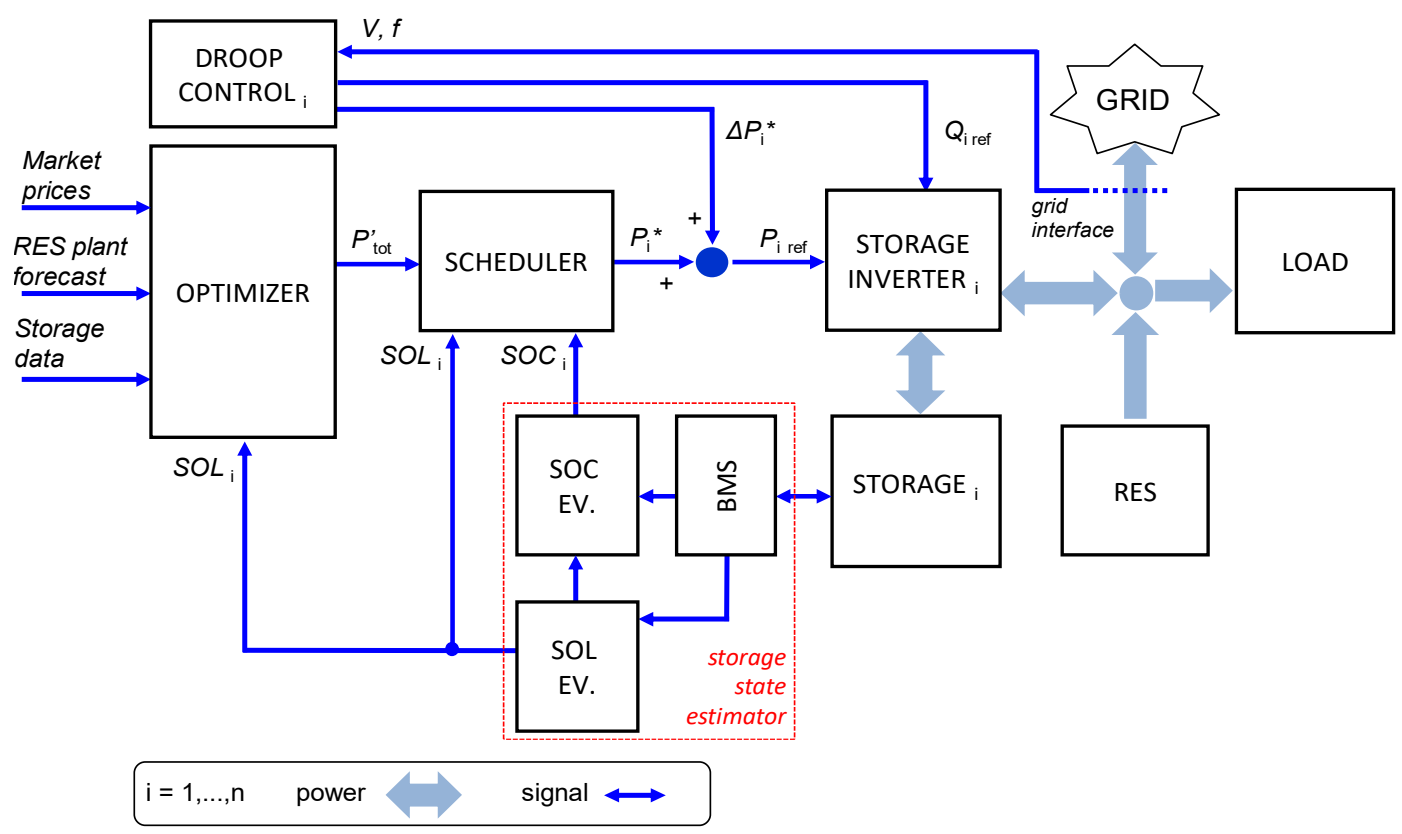

Figure 1. Control architecture

As described in [33], the main output of the control architecture is constituted by the reference power $P_{\mathrm{i}}$ ref to be sent to each storage inverter; in fact, the storage system has usually many branches. Each set-point $P_{\mathrm{i} \text { ref }}$ is determined by the combined action of the scheduler, which processes data from the optimizer and provides the best desired output $P_{\mathrm{i}}^{*}$ of each inverter, and of the droop control, which adds an active power correction $\Delta P_{\mathrm{i}}^{*}$ to each inverter, depending on the grid frequency for contributing to primary frequency regulation. In parallel, it also defines a reactive power reference $Q_{\mathrm{i} \text { ref, }}$ depending on the measured voltage.

Based on hourly market prices (supposed to be known for the following day as discussed below), on the forecast of the RES generation and on the storage features, the technical and economical optimizer evaluates the global amount of power $P_{\text {tot }}^{\prime}$ to be exchanged by the storage system at each quarter of an hour of the following day. Starting from this value, the scheduler divides $P_{\text {tot }}^{\prime}$ into different separated contributes $P_{\mathrm{i}}^{*}$, taking into account the actual State of Charge $\left(\mathrm{SOC}_{\mathrm{i}}\right)$ and State of Life $\left(\mathrm{SOL}_{\mathrm{i}}\right)$ of each storage branch. In addition to the SOC and SOL evaluators, a Battery Management System (BMS) monitors and equalizes cells and modules within each branch. Further details of each subsystem are provided in [33]. 


\section{The optimization procedure}

Figure 2 provides a graphical representation of the dynamic problem that has been implemented in JModelica [28] in order to optimize the operation of the storage devices of Figure 1, in the absence of a local load.

Assuming the PV power generated profile (output of the "PV spline" block) and the hourly purchase or sale electricity price (output of the "pricePurchase" or "priceSale" blocks) to be known over a daily horizon, the optimization algorithm determines the power that must be exchanged by the storage (output of "inFlowkW" block) in order to maximize the total daily profit (output of the "\$\$" block).

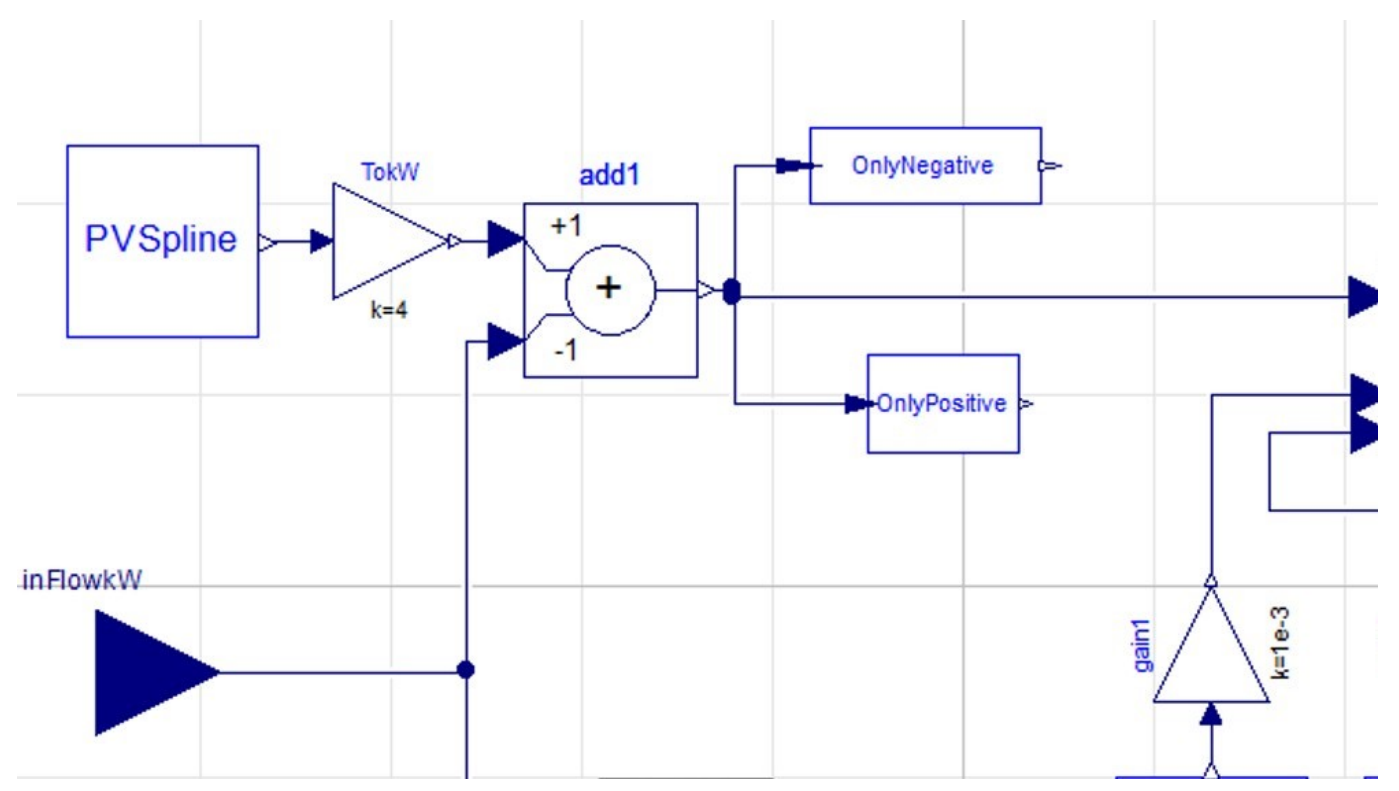

Figure 2. Graphical description of the optimization problem, according to the architecture depicted in Figure 1 (without load)

In order to optimize the daily operation of the storage (Rechargeable Energy Storage System, RESS), the proposed algorithm works under the following hypotheses:

- The PV power profile of the next hours is assumed to be forecasted by means of a common short term algorithm [34]. Conversely, assuming to run the algorithm during the afternoon of day D-1, the hourly electricity prices of day D are well known and have not to be forecasted, since already issued by the Day-Ahead electricity Market. 
- Regarding storage losses, two criteria have been used. Firstly, constant round trip efficiency was supposed, as usual in the literature. Then, a more detailed model of storage efficiency was developed, assuming power losses to be partially proportional to the power absorbed or delivered by the storage (power electronics) and partially dependent on the square of such a power (resistive losses) [35].

- As an additional constraint to the optimization, it was imposed initial and final Level Of Energy (LOE), i.e. the ratio between the stored energy and the nominal energy of the RESS, must correspond over a 24 hours period.

- The daily revenue to be maximized, $R$, is evaluated according to the following formula:

$$
R=\sum_{t=1}^{24}\left[\left(P_{P V}(t)-P_{R E S S}(t)\right) \cdot c_{E}(t)\right]
$$

where $t$ is the considered time step (one hour), $P_{P V}$ is the hourly profile expected to be generated by the solar panels, $P_{R E S S}$ is the hourly energy exchanged by the RESS (conventionally positive when adsorbed by the RESS and negative when provided), and $c_{E}$ is the hourly purchase or sale price of energy, in $€ / \mathrm{kWh}$. The price $c_{E}$ considered by the optimization procedure depends on the algebraic sum of $P_{P V}$ and $P_{R E S S}$ : when that sum is positive, energy is sold to the grid, so "priceSale" is used; conversely, when that sum is negative, energy is purchased from the grid and "pricePurchase" is considered.

When the local load is included, the optimization problem becomes as shown in Figure 3.

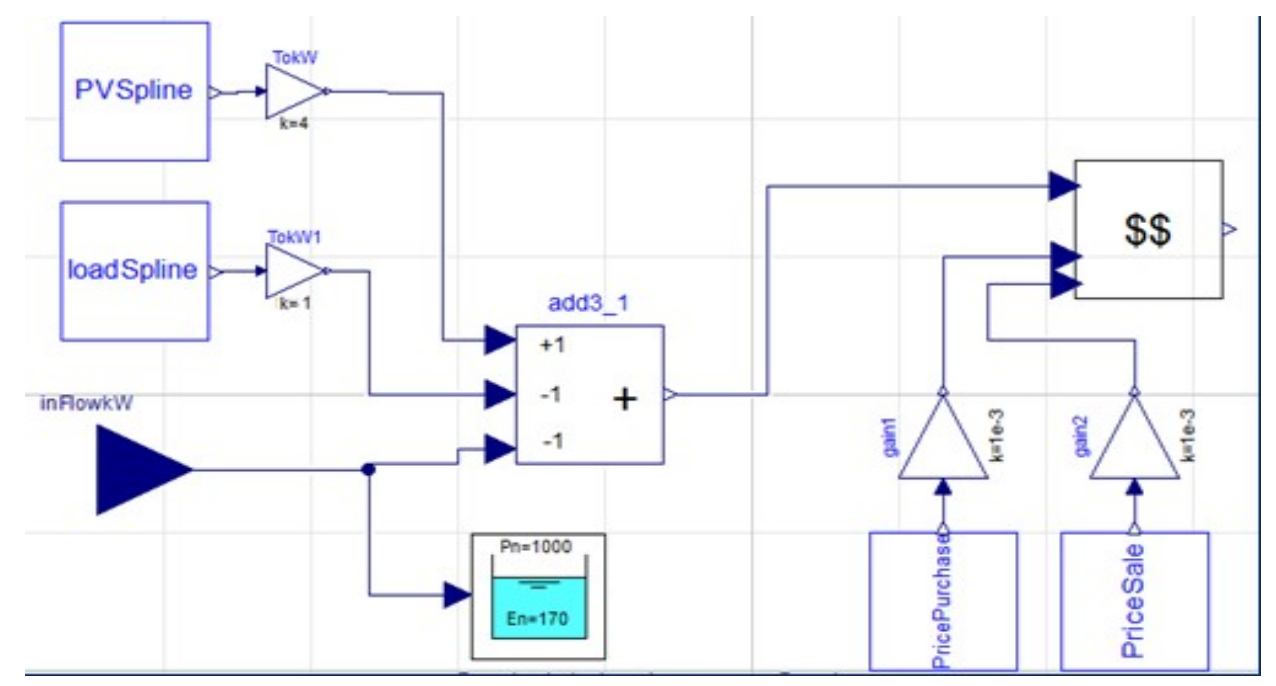

Figure 3. Graphical description of the optimization problem, according to the architecture depicted in Figure 2 (with load) 
As visible, the general structure does not change with respect to Figure 2, apart from the addition of the "loadSpline" block. The same hypotheses of the previous case have been assumed, but the daily revenue to be maximized, $R$, is now evaluated according to the following formula:

$$
R=\sum_{t=1}^{24}\left[\left(P_{P V}(t)-P_{L}(t)-P_{R E S S}(t)\right) \cdot c_{E}(t)\right]
$$

Where $t$ is the considered time step (one hour), $P_{P V}$ is the hourly profile expected to be generated by the solar panels, $P_{L}$ is the forecasted hourly load, $P_{R E S S}$ is the hourly energy exchanged by the RESS (conventionally positive when adsorbed by the RESS and negative when provided), and $c_{E}$ is the hourly purchase or sale price of energy, in $€ / \mathrm{MWh}$. As in the previous case, the price considered by the optimization procedure depends on the sign of the energy exchanged with the grid $\left(P_{P V}-P_{L}-P_{R E S S}\right)$; when this term is positive, energy is sold to the grid and "priceSale" is used; conversely, when energy is purchased from the grid "pricePurchase" is considered. In other terms, the problem formalization exactly reproduces what already shown in (1), with the simple addition of $P_{L}$.

The two presented optimization problems have been solved using the Modelica language, which has several useful features for simulation of complex engineering systems and very recently has been extended from time-domain simulation to dynamical optimization studies. A description of the used optimization tool is reported in the next paragraph.

\section{The optimization tool}

The dynamic optimization of the operation of storage devices has been performed through JModelica [28], a specific platform based on Modelica language. One of the main features of JModelica is Optimica [36], an additional tool specifically deployed for solving optimization problems.

Based on the experience collected by the authors using the OpenModelica standard optimisation tool [7], JModelica allows to overcome well-known problems of no-convergence and gives much more control on optimisation parameters. In fact, JModelica interacts with the user through Python language [36] and provides the user with many optimization options, i.e. number of finite elements, number of collocation points, algorithms, etc. 
The dynamic optimization problem is formally described by the following equation:

$\min _{u(t)} C\left(x_{\left(t_{f}\right)}, t_{f}, u_{\left(t_{f}\right)}\right)+\int_{t_{i}}^{t_{f}} F\left(x_{(t)}, u_{(t)}, t\right) d t$

Where $C$ is the function to be minimised, $t \in\left[t_{i}, t_{f}\right]$ is the time interval, $x(t) \in \mathbb{R}^{n_{x}}$ are the state variables, $u(t) \in \mathbb{R}^{n_{u}} u(t) \in \mathbb{R}^{n_{u}}$ are the control variables. In order to complete the mathematical formulation, the initial conditions (4a), the model description by Differential-Algebraic Equation (DAE) shown in (4b), the path constraints (4c), and the final constraints (4d) are also required.

$0=\mathrm{r}_{0}\left(x_{\left(t_{0}\right)}, t_{0}\right)$

$0=\hat{f}(x(t), \dot{x}(t), u(t), t)$

$0 \leq \mathrm{g}(x(t), \dot{x}(t), u(t), t)$

$0=r_{f}\left(x\left(t_{f}\right), u\left(t_{f}\right), t_{f}\right)$

The problem can be solved by collocation methods; in order to optimize the case study proposed in this paper, the Radau collocation scheme (Legendre-Gauss-Radau) [37] was used to discretize the state and control variables, and the optimizer ipopt [38] to solve the discrete problem. After defining the simulation model and the optimization parameters (target, variables, constraints, etc.), the process requires several iterations before the convergence is reached. The solution is saved in a text file that contains all trajectories of model variables; the results can be also shown by the graphical user interface (GUI) of JModelica [28].

Moving from the general formalisation to the considered case study, the function to be minimized is the inverse of the revenue $R$, as inferred from (1) and (2) where the maximization of the revenue $R$ is considered. The control variable $u(t)$ is represented as the power $P_{\text {RESS }}$ exchanged from the RESS. The DAE system (4b) consists of equations for each sub-model, to complete the full models depicted in Figure 2 and Figure 4. Initial (4a) and final conditions (4c) have been imposed for LOE, giving upper and lower limits, while maximum values for power $P_{R E S S}$ and energy $E_{R E S S}$ were imposed as path constraints (4d). The time interval under optimization is from $00 \mathrm{AM}$ to $12 \mathrm{PM}$. 


\section{Case studies}

For each configuration (without load, Figure 2, and with local load, Figure 3), two possible sizing of the RESS have been tested. In the first case, the RESS was sized at $1000 \mathrm{~kW}$ and $170 \mathrm{kWh}$, in terms of maximum power exchange and stored energy respectively, as in the reference plant [33]; a second storage configuration, with the same power rating but a larger capacity (500 kWh), was then simulated.

The power profile expected to be generated by the PV plant actually derives from the measurements taken an existing 3,7-MW power plant [33]. Regarding storage losses, constant round trip efficiency of 95\% was firstly supposed; with the more complex non-linear model of storage losses described in Section 2, power losses at nominal power are $7 \%$ and, according to off-line simulations, the round trip efficiency corresponds to $86 \%$.

Figure 4 reports the price patterns assumed for purchase and sale of electricity; they are constituted by a single price cycle during the day and have been calibrated on typical Italian values. As usual in case of high PV penetration, price curves with a day/night price spread larger than in [6] have been used.

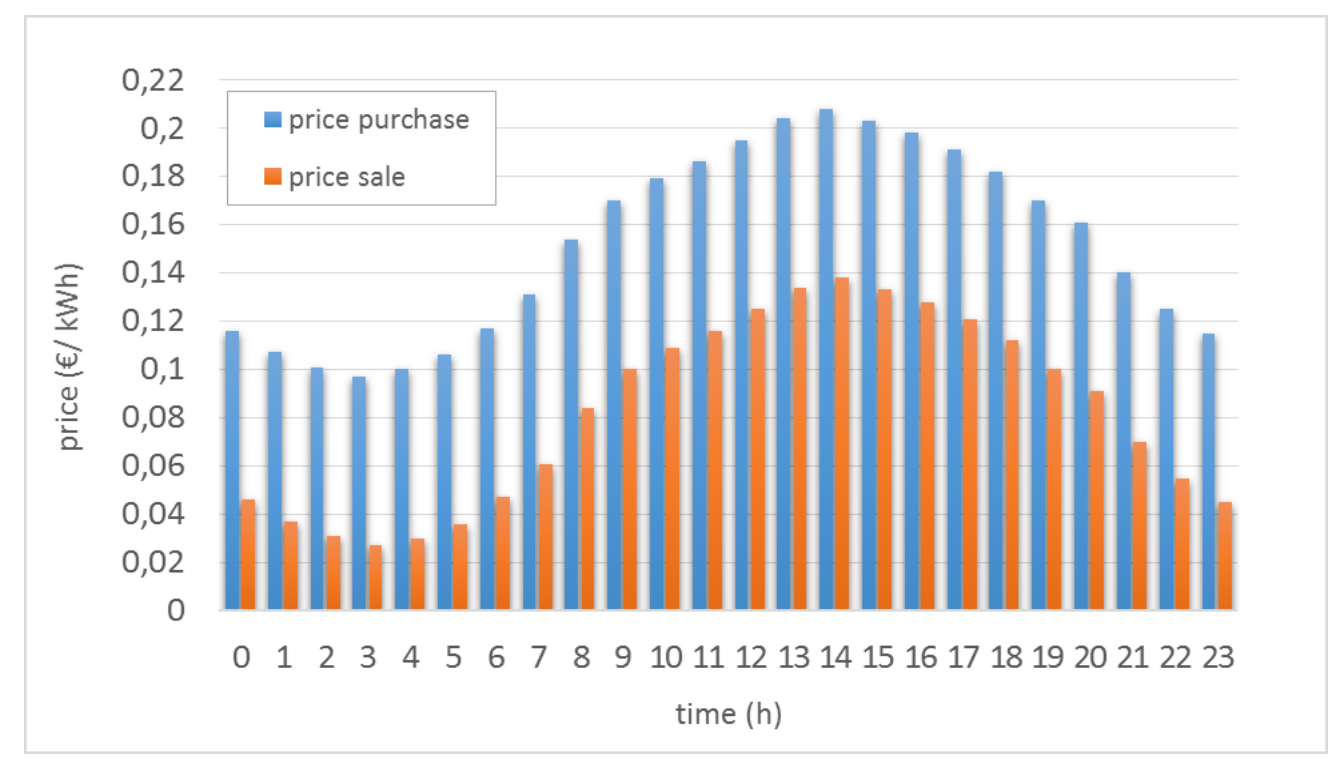

Figure 4. Cost price of energy

First of all the results corresponding to the optimization problem depicted in Figure 1 will be shown and commented. 


\subsection{Configuration without load}

The results related to a PV plant without load have been analysed with reference to the four storage configurations previously described. First, the results related to the $170-\mathrm{kWh}$ energy storage, assuming constant round trip efficiency, are depicted in Figure 5, where "net power" is the power delivered to the grid and "RESS power" is the power absorbed by the storage device.

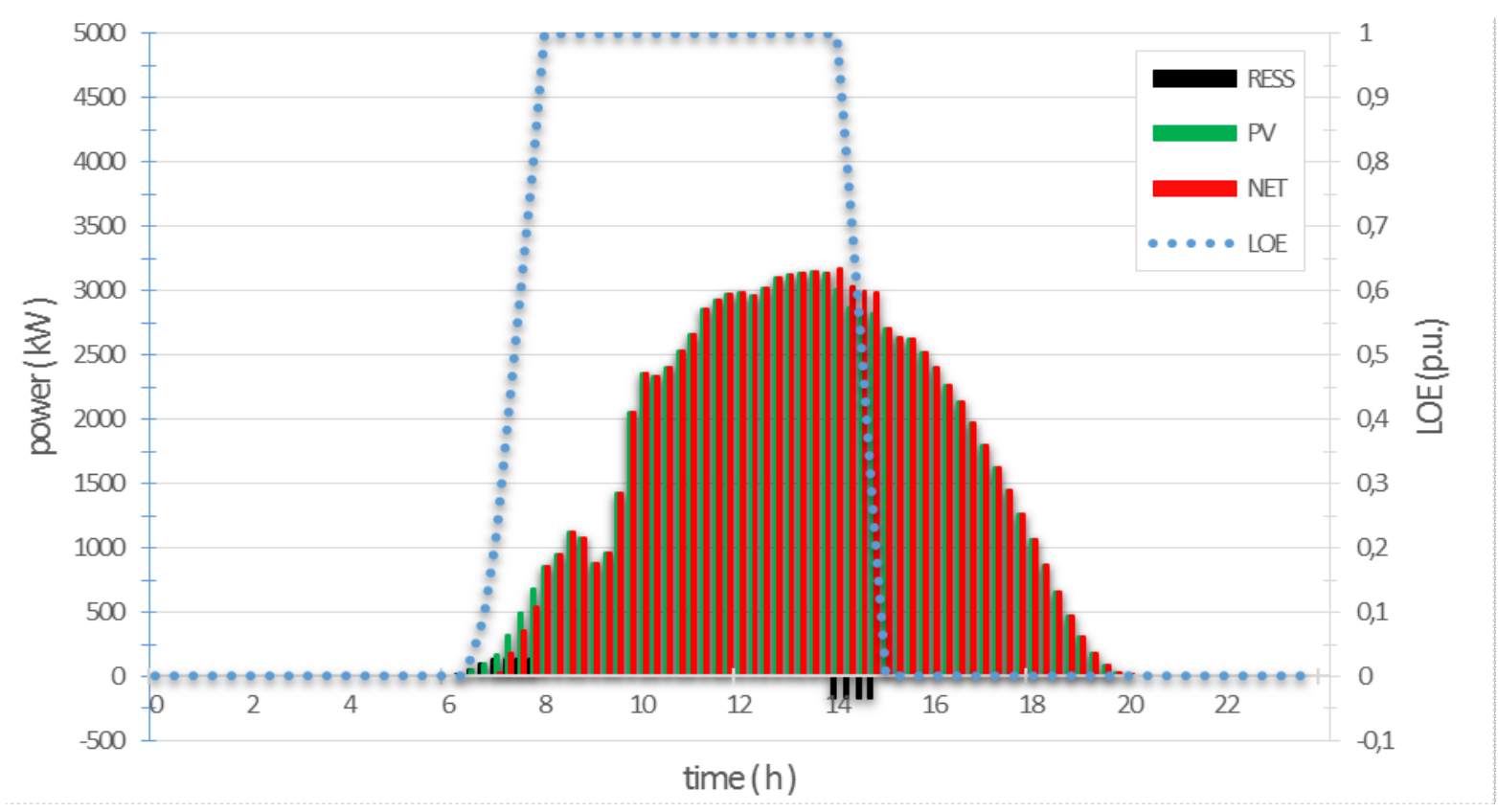

Figure 5. Optimal storage operation, configuration without load, 170-kWh energy storage, constant round trip efficiency

Figure 5 clearly shows that the RESS is operated as soon as the photovoltaic panels start producing, in order to defer the delivery of PV energy to the grid to the hours with the highest prices. The maximum power during the charging operation is limited to $140 \mathrm{~kW}$, due to the reduced energy volume of RESS. The battery is completely charged between $6 \mathrm{AM}$ and $8 \mathrm{AM}$. Then, the RESS delivers electricity to the grid between $2 \mathrm{PM}$ and $3 \mathrm{PM}$, when the sale price reaches its maximum value, as shown in Figure 4. It is worth noticing that, since energy losses do not depend on the power delivered by the storage device, different power profiles would be acceptable as well, while guaranteeing the full discharge within the same hour. In the shown case, discharge power reaches $166 \mathrm{~kW}$. 
When losses are assumed to depend on the power exchanged by the RESS, charging operation is practically unchanged with respect to the previous case, since the power profile is substantially imposed by the PV system. Conversely, discharging operation is spread in two consecutive hours (1 PM - 3 PM), in order to limit power to $151 \mathrm{~kW}$, which corresponds to the best compromise between efficiency and prices.

When the larger battery is used $(500 \mathrm{kWh})$, the charging operation is spread on a longer period (6 AM$9 \mathrm{AM}$ ), due to the higher energy volume to be filled. The discharging operation is still located in the time range 2 PM-3 PM (the hour with the highest sale price), since the rated power of the RESS allows to fully discharge the battery in one hour and losses are not penalized by the high value of exchanged power.

Conversely, assuming losses to be dependent on the power exchanged by the RESS, the optimizer avoids concentrating the exchange of significant energy amounts in few hours; hence charging/discharging operations are spread on more hours, adjacent to the ones of minimum/maximum price. In the considered case, as shown in Figure 6, the charging operation remains substantially unaltered, while discharging is spread on a longer time range (1-4 PM).

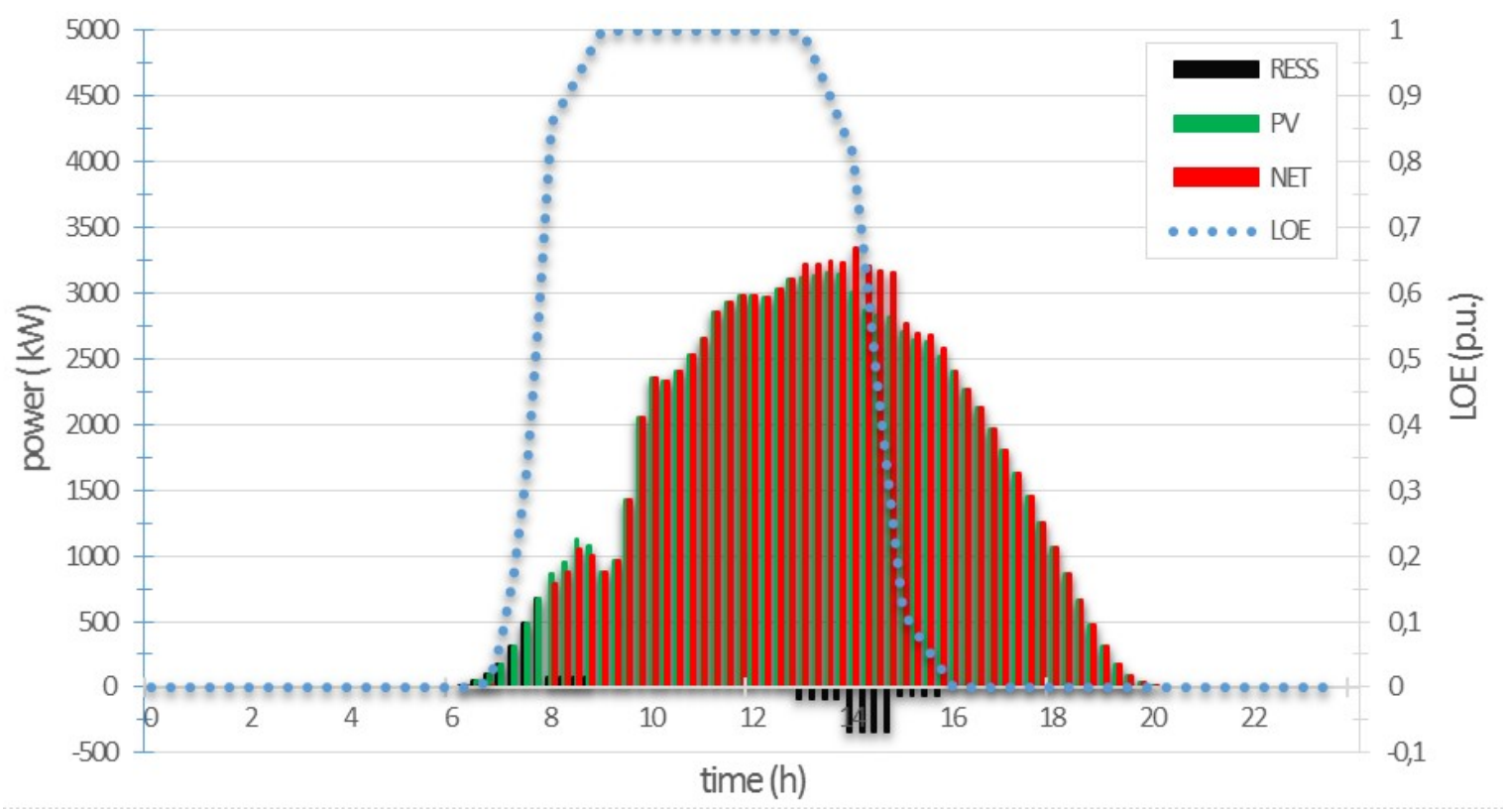

Figure 6. Optimal storage operation, configuration without load, 500-kWh energy storage, storage losses dependent on exchanged power 
Figure 7 shows the optimal operation of the $170-\mathrm{kWh}$ energy storage, assuming the control architecture described in Figure 2 and that the round trip efficiency is constant. Regarding the load, a power profile corresponding to an industrial facility has been assumed [7], as depicted in Figure 7.

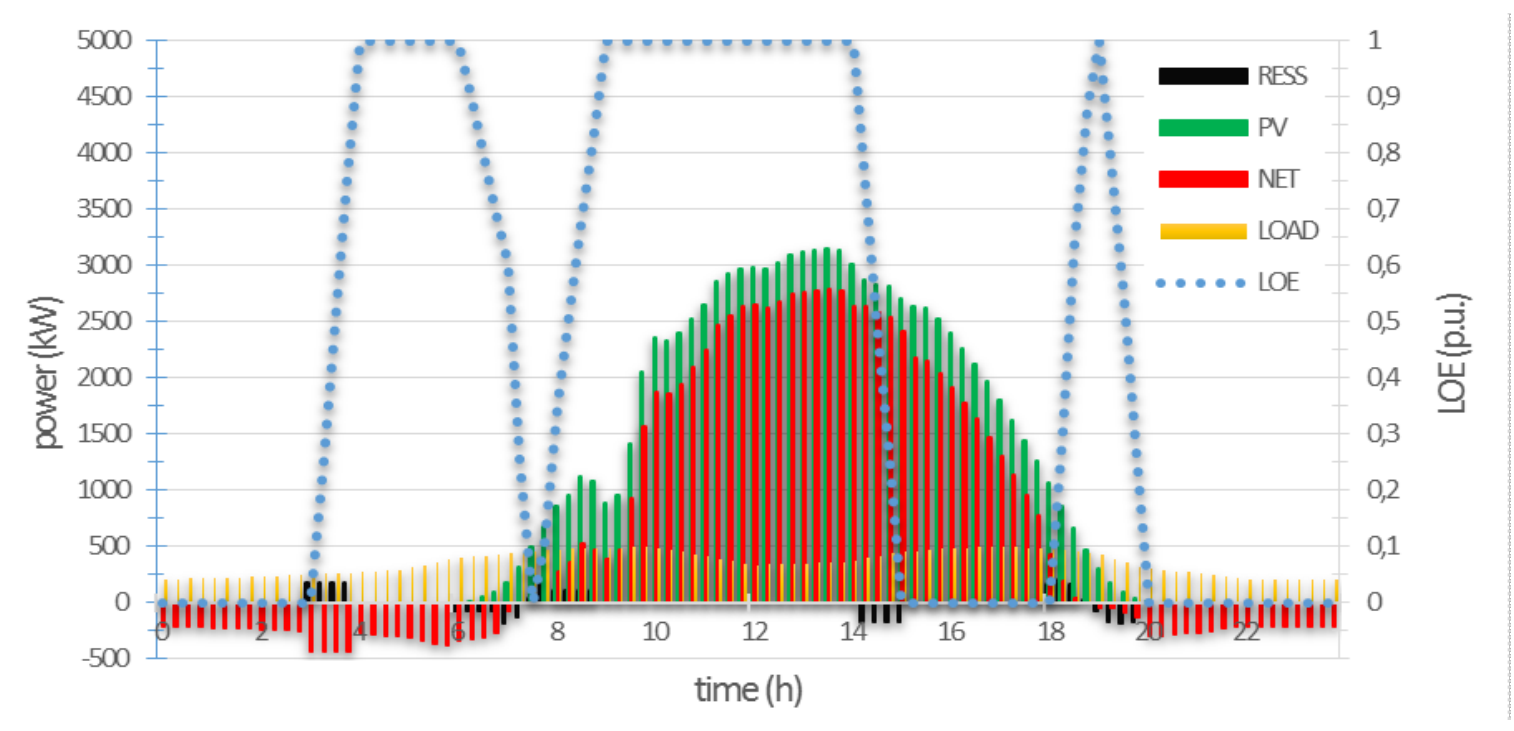

Figure 7. Optimal storage operation, configuration with load, $170-k W h$ energy storage, constant round trip efficiency

When the load is considered, the operation of the RESS is definitely more complex, resulting both from price considerations and on the comparison between the load and the PV production. Since during the night the PV production is null, the optimizer decides to charge the RESS between $3 \mathrm{AM}$ and $4 \mathrm{AM}$, at the minimum electricity purchase price. When the load request increases and the PV production is still significantly lower than the load request, the RESS is fully discharged, thus avoiding purchasing that energy from the grid at a higher price (6 AM-7:30 AM). When the PV generation becomes higher than the load request (7:30 AM-9 AM), the RESS is recharged by the panels. The following RESS discharge is concentrated, as in the previous cases, between 2 PM and 3 PM, when the highest sale price is reached. When, at 6 PM, the PV production falls below the load request, the RESS is fully recharged by the panels, in order to be able to feed the load, and partially avoiding the purchase of electricity from the grid, at the following hour (7 PM - 8 PM). 
If energy losses are assumed to be dependent on the power exchanged by the RESS, the optimal operation of the storage device is slightly different. In particular, the first charging operation and the discharge activated at the maximum sale price are spread on two adjacent hours, remaining in any case substantially centered in the time range 3 AM-4 AM and 2 PM-3 PM respectively. The other discharging and charging operations are practically unaltered, since spreading them on more hours would increase the average energy efficiency but at the expense of the obtained prices.

When the larger battery is used $(500 \mathrm{kWh})$, the first discharging operation is longer, starting at 6:15 AM. The first charging operation (at minimum purchase price) and second discharging operation (at maximum sale price) are unaltered with respect to the previous case, since the power rating of the RESS allows to fully charge or discharge the RESS in a single hour.

Finally, assuming losses to be dependent on the power exchanged by the RESS, the optimizer avoids the concentration of significant energy amounts in few hours, thus spreading charging/discharging operations on more hours, adjacent to the ones of minimum/maximum price. In the considered case, whose results are shown in Figure 8, first charging operation at minimum purchase price and second discharging operation at maximum higher sale price are spread in three hours: from $2 \mathrm{AM}$ to $5 \mathrm{AM}$ and from $1 \mathrm{PM}$ to $4 \mathrm{PM}$, respectively).

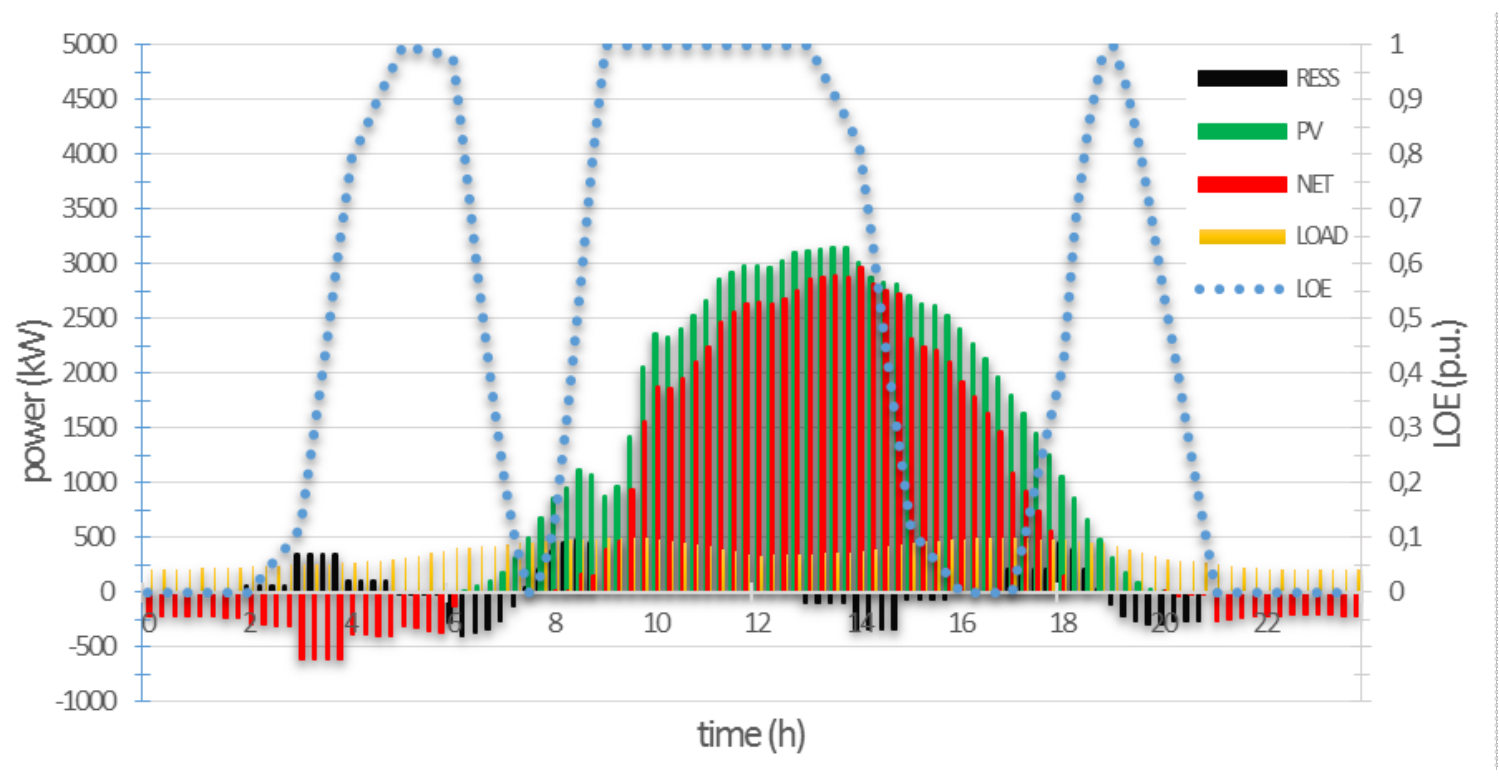

Figure 8. Optimal storage operation, configuration with load, 500-kWh energy storage, storage losses dependent on exchanged power 


\subsection{Economic analysis}

Revenues were evaluated by the " $\$ \$$ " block shown in Figure 2 and Figure 4. Results from different configurations have been compared to the reference revenue evaluated in the absence of the RESS, with or without load. The economic benefit of each storage solution is then evaluated and compared to the relevant investment, estimated by a fixed price of $400 € / \mathrm{kWh}$ including BMS, considering a lithium cell typology for stationary applications. The following variants have been considered, results are summarized in Table 1.

- Reference configuration, without storage system.

- System without load, with $170 \mathrm{kWh}$ or $500 \mathrm{kWh}$ energy storage, having round trip efficiency (respectively A and C variants) or losses dependent on power (respectively B and D).

- System with load, with $170 \mathrm{kWh}$ or $500 \mathrm{kWh}$ energy storage, having round trip efficiency (respectively $\mathrm{E}$ and $\mathrm{G}$ variants) or losses dependent on power (respectively $\mathrm{F}$ and $\mathrm{H}$ variants). 
Table 1. Economic analysis

\begin{tabular}{|c|c|c|c|c|c|}
\hline & $\begin{array}{c}\text { RESS } \\
\text { size } \\
(\mathrm{kWh}) \\
\end{array}$ & $\begin{array}{l}\text { RESS } \\
\text { cycles } \\
\text { (\#/day) } \\
\end{array}$ & $\begin{array}{c}\text { RESS } \\
\text { price } \\
(\mathrm{k} €) \\
\end{array}$ & $\begin{array}{c}\text { Total } \\
\text { revenue } \\
(€ / \text { day })\end{array}$ & $\begin{array}{l}\text { Benefit } \\
(€ / \text { day })\end{array}$ \\
\hline \multicolumn{6}{|c|}{ without Load } \\
\hline $\begin{array}{l}\text { Reference } \\
\text { (no storage) }\end{array}$ & - & - & - & 2945 & - \\
\hline $\begin{array}{l}\text { Configuration A } \\
\text { (round trip } \\
\text { efficiency) }\end{array}$ & \multirow{2}{*}{170} & \multirow{2}{*}{1} & \multirow{2}{*}{68} & 2961 & 16 \\
\hline $\begin{array}{c}\text { Configuration B } \\
\text { (losses dependent } \\
\text { on power) }\end{array}$ & & & & 2969 & 24 \\
\hline $\begin{array}{l}\text { Configuration } \mathrm{C} \\
\text { (round trip } \\
\text { efficiency) }\end{array}$ & \multirow{2}{*}{500} & \multirow{2}{*}{1} & \multirow{2}{*}{200} & 2984 & 39 \\
\hline $\begin{array}{l}\text { Configuration D } \\
\text { (losses dependent } \\
\text { on power) }\end{array}$ & & & & 2990 & 45 \\
\hline \multicolumn{6}{|c|}{ with Load } \\
\hline $\begin{array}{l}\text { Reference } \\
\text { (no storage) }\end{array}$ & - & - & - & 1954 & - \\
\hline $\begin{array}{l}\text { Configuration E } \\
\text { (round trip } \\
\text { efficiency) } \\
\end{array}$ & \multirow{2}{*}{170} & \multirow{2}{*}{3} & \multirow{2}{*}{68} & 1987 & 33 \\
\hline $\begin{array}{l}\text { Configuration F } \\
\text { (losses dependent } \\
\text { on power) }\end{array}$ & & & & 1987 & 33 \\
\hline $\begin{array}{l}\text { Configuration } \mathrm{G} \\
\text { (round trip } \\
\text { efficiency) }\end{array}$ & \multirow{2}{*}{500} & \multirow{2}{*}{3} & \multirow{2}{*}{200} & 2011 & 57 \\
\hline $\begin{array}{l}\text { Configuration } \mathrm{H} \\
\text { (losses dependent } \\
\text { on power) }\end{array}$ & & & & 2016 & 62 \\
\hline
\end{tabular}

In the configurations without local load, the extra revenue generated by the operation of the storage increases when losses are assumed to be dependent on power; in fact, at the low average power at which the storage device is operated, with the detailed model losses result to be lower than assuming a constant round rip efficiency. In terms of storage size, enhancing the energy capacity from $170 \mathrm{kWh}$ to $500 \mathrm{kWh}$ increases the investment costs by 2,9 times, while operational benefits increase only by 1,2-1,5 times, depending on losses evaluation. Payback time is then shorter with the smaller storage.

When a local load is considered, the extra revenues generated by the storage increase in any scenario of size and losses. With a load, in fact, the added value of the storage is not only maximizing energy sales at the highest prices, but also increasing the auto-consumption of PV production; it is worth remembering that 
avoided purchase costs are higher than sales revenues. When the load is considered, the extra revenues generated by the storage are less dependent on the model used to assess energy losses; this is due to the fact that the average operation of the storage is close to the break even point of the two losses models. Also in this case, the smaller storage is more cost effective, due to a best utilization of its capacity.

Based on revenues shown in Table 1, the evaluation of Net Present Value (NPV), Internal Rate of Return (IRR) and Payback Time (PBT) of the storage device has been performed for the most promising solution, i.e. the $170-\mathrm{kWh}$ plant, operated when the load is considered. The analysis, whose results are shown in Table 2, was focused on 10 years of storage operation, corresponding to 10800 battery cycles ( 3 cycles/day, 360 days/year). Two different limits of Depth Of Discharge (DOD) were also imposed to the optimizer: $80 \%$ and $50 \%$. In the first case, assuming a lifetime of $5 \cdot 10^{3}$ cycles according to manufacturer data [39], representing one cheap lithium cell technology, one battery substitution is required after five years, at the current state of technology. Alternatively, it is possible to operate the same storage for 10 years, by reducing DOD to $50 \%$, i.e. assuming a lifetime of more than $10^{4}$ cycles, from reasonable trend always evaluated by [39] and experiences made by the authors [40]. As visible, DOD at 100\% was not considered in the present analysis, since it should require the substitution of the storage almost every year. Economic calculations were performed assuming a discount rate of $4 \%$.

Table 2 clearly shows that by imposing a limit to the DOD the daily benefit generated by the operation of the storage decreases, but the lifetime and the cost effectiveness of the device significantly increase. At the present costs of the storage, the investment becomes cost effective only with a DOD of $50 \%$.

Table 2. PBT, NPV, IRR evaluation at present storage installation costs $-170 \mathrm{kWh}$ with load

\begin{tabular}{|c|c|c|c|c|c|}
\hline DOD & $\begin{array}{c}\text { Storage } \\
\text { benefit } \\
(€ / \text { day })\end{array}$ & $\begin{array}{c}\text { Storage } \\
\text { benefit } \\
(€ / \text { year })\end{array}$ & PBT & NPV & IRR \\
$(\mathrm{kear})$ & $(\mathrm{k} €)$ & $(\%)$ \\
\hline $80 \%$ & 30 & 10800 & - & -31567 & $-8,9$ \\
\hline $50 \%$ & 24 & 8640 & 9,6 & 1998 & 4,6 \\
\hline
\end{tabular}

It can be of a certain interest to recalculate NPV, IRR and PBT considering the future trends expected for the technology of lithium batteries. In the near future, it is reasonable to expect that conventional lithium cells will be capable of at least $10^{4}$ charging-discharging cycles with a DOD of $80 \%$, as already obtainable 
today with the most expensive lithium cell technology [41]. This would be sufficient to operate the storage device for 10 years (10800 cycles). Additionally, a significant reduction of installation costs was assumed, from $400 € / \mathrm{kWh}$ to $300 € / \mathrm{kWh}$, according to the future trend of battery costs, expected for the next ten years [42] [43]. With these assumptions, PBT, NPV and IRR change as shown in Table 3. Daily storage benefits are unaltered with respect to Table 2.

Table 3. PBT, NPV, IRR evaluation at possible future installation costs $-170 \mathrm{kWh}$ with load

\begin{tabular}{|c|c|c|c|}
\hline DOD & $\begin{array}{c}\text { PBT } \\
(\text { year })\end{array}$ & $\begin{array}{c}\text { NPV } \\
(\mathrm{k} €)\end{array}$ & $\begin{array}{c}\text { IRR } \\
(\%)\end{array}$ \\
\hline $80 \%$ & 5,3 & 35190 & 16,6 \\
\hline $50 \%$ & 6,9 & 42528 & 15,7 \\
\hline
\end{tabular}

As visible, the decrease of installation costs and the increase of battery lifetime reduce PBT to 5,3 years with DOD of $80 \%$, and to 6,9 years in case of DOD limited at $50 \%$. In this last case, NPV and IRR have been calculated also taking into account the economic residual value of the storage at the reference threshold of 10 years; in fact, after 10800 charging-discharging cycles, about $3 \cdot 10^{4}$ more cycles $(3 / 4$ of the battery lifetime) would be still possible.

In a future perspective, the cost effectiveness of both solutions significantly increases. In particular, the operation with DOD limited at 50\% shows the maximum NPV, due to the fact that the lifetime of batteries increases more that proportionally than the limitation imposed to DOD. 


\section{Conclusions}

This paper has proposed a new technique to optimise the operation of a storage device coupled with a PV generating plant, with the possible presence of a local load. The dynamic programming tool here implemented in Modelica and applied for the first time to the optimal operation of an electrochemical storage has proved to be fully adequate to this purpose, in terms of flexibility, stability and computational time. The tool has provided solutions that exploit the full potential of multiple bidirectional energy exchanges between the PV plant, the load and the power network; this is significantly beyond the traditional techniques that simply maximise the self-consumption of photovoltaic energy.

The results of performed simulations have shown first of all the strict dependence of the optimal power profile of the storage device on the degree of accuracy with whom its losses are modeled. The usual model of constant round-trip efficiency stimulates the operator to concentrate charging and discharging power during the few hours with extremes electricity prices. Conversely, when adopting a more accurate non-linear model for losses, it turns out that the best strategy is spreading the energy exchanged by the storage in more consecutive hours, in order to limit power and losses; in this regard, the optimization technique here proposed has proved to be perfectly able to calibrate this spreading, finding the most profitable compromise between efficiency and electricity prices.

The constraint imposed to the maximum allowed depth of discharge of the storage has itself been object of fine-tuning, this time on a long term perspective. The most profitable compromise between the effective exploitation of the storage capacity and the safeguard of battery lifetime was found focusing on the cash flows of 10 years of operation, with multiple battery replacements if required. The results of the proposed case studies have shown the cost-effectiveness of the smaller storage solution, to be accurately managed by adequately limiting its depth of discharge during daily operation.

Considering current investment costs of storage devices, the profitability of price arbitrage is still borderline, since strictly depending on electricity price patterns and generation/consumption power profiles. As simulated in the final part of this paper, future trends of technology and costs should increase the competitiveness of these business solutions, reducing payback time to around a half of the operational life. 


\section{References}

[1] H. I. Su and A. El Gamal, "Modeling and analysis of the role of energy storage for renewable integration: power balancing,” IEEE Trans. Power Systems, vol. 28, no.4, pp. 4109-4117, 2013.

[2] S.Barsali, M.Ceraolo, R,Giglioli, D.Poli, "Storage applications for smartgrids", Electric Power System Research (EPSR), Vol.120, March 2015, pages 109-117.

[3] M.Brenna, F.Foiadelli, M.C.Falvo, L.Martirano, D.Poli, "Sustainable Energy Microsystem (SEM): Preliminary Energy Analysis”, 2012 IEEE PES Conference on Innovative Smart Grid, January 16-20 2012, Washington.

[4] M.Brenna, M.C.Falvo,F.Foiadelli, L.Martirano, F.Massaro, D.Poli, A.Vaccaro, "Challenges in Energy Systems for the Smart-Cities of the Future", IEEE Energycon 2012, 9-12 September 2012, Florence.

[5] P. van de Ven, N. Hegde, and L. Massouli'e and T. Salonidis, "Optimal control of end-user energy storage,” IEEE Trans. Smart Grid, vol. 4, no. 2, pp. 789-797, 2013.

[6] S.Barsali, R.Giglioli, G.Lutzemberger, D.Poli, "Optimal storage operation in EV charging stations delivering grid services", 2016 IEEE 16th International Conference on Environment and Electrical Engineering (EEEIC), 7-10 June 2016, Florence, Italy.

[7] B. Bachmann, M. Ceraolo, G. Lutzemberger, D. Poli, V. Ruge: "Dynamic optimisation of price arbitrage techniques”, International Forum on Research and Technologies for Society and Industry (RTSI), 2016 IEEE, 7-9 Sept. 2016, Bologna.

[8] M.Brenna, M.C.Falvo, F.Foiadelli, L.Martirano, D.Poli, "From Virtual Power Plant (VPP) to Sustainable Energy Microsystem (SEM): an opportunity for buildings energy management", 2015 IEEE Industry Applications Society Annual Meeting, October 18-22, Dallas.

[9] Y. Xu and L. Tong, "On the operation and value of storage in consumer demand response," in Proc. of 53th IEEE Conference on Decision and Control (CDC), pp. 205-210, 2014. 
[10] Worthmann, K.; Kellett, C.M.; Braun, P.; Grune, L.; Weller, S.R. Distributed and decentralized control of residential energy systems incorporating battery storage, IEEE Trans. Smart Grid 2015, 6(4).

[11] J. H. Kim and W. B. Powell, "Optimal energy commitments with storage and intermittent supply," Operations Research, vol. 59, no. 6, pp. 1347-1360, 2011.

[12] N. Gast, D. C. Tomozei, and J. Y. Le Boudec, "Optimal generation and storage scheduling in the presence of renewable forecast uncertainties," IEEE Trans. Smart Grid, vol. 5, no.3, pp. 1328-1339, 2014.

[13] K. Rahbar, J. Xu, and R. Zhang, "Real-time energy storage management for renewable integration in microgrid: an off-line optimization approach,” IEEE Trans. Smart Grid, vol. 6, no. 1, pp. 124-134, 2015.

[14] S. Lakshminarayana, Y. Xu, H. V. Poor, and T. Q. Quek, "Cooperation of storage operation in a power network with renewable generation,” IEEE Trans. Smart Grid, vol. 7, no. 4, pp. 2108-2122, 2016.

[15] Hong Yuan; Jianxiang Li; Bingliang Zhang; Haibo Liu; Xu Zhang; Bohao Sun; Shenquan Yang. A dynamic optimal control strategy for BESS considering wind power forecasting. In Proceedings of IEEE International Conference on Mechatronics and Automation (ICMA), Tianjin, 3-6 Aug.2014, pp. 2072 2076.

[16] Xu, N.Z.; Ming Ding; Chung, C.Y. Control strategies of BESS for compensating renewable energy fluctuations. In Proceedings of the $9^{\text {th }}$ IET International Conference on Advances in Power System Control, Operation and Management (APSCOM), Hong Kong, 18-21 Nov. 2012; pp 1 - 5.

[17] Lei Zhang; Yipeng Dong; Zhigang Chen; Xiaorong Xie; Hao Sun; Zhiwen Liu. An integrated control strategy of battery energy storage system in microgrid. In Proceedings of the IET Renewable Power Generation Conference (RPG), Beijing, 9-11 Sept. 2013; pp. 1 - 4.

[18] Nottrot, A.; Kleissl, J.; Washom, B. Energy dispatch schedule optimization and cost benefit analysis for grid-connected, photovoltaicbattery storage systems, Renewable Energy 2013, 55, 10.1016/j.renene.2012.12.036. 
[19] Jiangliang Jin; Yunjian Xu; Yawar Khalid; Naveed UL Hassan, Optimal Operation of Energy Storage with Random Renewable Generation and AC/DC Loads, to be published on IEEE Transactions on Smart Grid, 2016. DOI: 10.1109/TSG.2016.2611245

[20] M.Giuntoli, D.Poli, "Optimized thermal and electrical scheduling of a Large Scale Virtual Power Plant in the presence of energy storages”, IEEE Transactions on Smart Grid, Vol.4 Issue 2, June 2013.

[21] R.Martins, P.Musilek, H.C.Hesse, Optimization of photovoltaic power self-consumption using linear programming, IEEE 16th International Conference on Environment and Electrical Engineering (EEEIC), 2016.

[22] M.Brenna, F.Foiadelli, M.Longo, D.Zaninelli, Energy Storage Control for Dispatching Photovoltaic Power, to be published on IEEE Transactions on Smart Grid, 2016, DOI: 10.1109/TSG.2016.2611999.

[23] X. Xi, R. Sioshansi, and V. Marano, “A stochastic dynamic programming model for co-optimization of distributed energy storage,” Energy Systems, vol. 5, no. 3, pp. 475-505, 2014.

[24] J.Qin, R.Sevlian, D.Varodayan, R.Rajagopal, Optimal electric energy storage operation, 2012 IEEE Power and Energy Society General Meeting

[25] B.W.Abegaz; S.M.Mahajan, Optimal dispatch control of energy storage systems using forwardbackward induction, 2015 International Conference on Clean Electrical Power (ICCEP).

[26] P. Harsha and M. Dahleh, "Optimal management and sizing of energy storage under dynamic pricing for the efficient integration of renewable energy," IEEE Trans. Power Systems, vol. 30, no.3, pp. 1164-1181, 2015.

[27] P. Fritzson, "Introduction to Modeling and Simulation of Technical and Physical Systems with Modelica”, Wiley-IEEE Press, September 2011.

[28] JModelica.org, User guide, http://www.jmodelica.org/api-docs/usersguide/JModelicaUsersGuide1.9.1.pdf 
[29] F. Casella, F. Donida, J. Akesson, "Object-Oriented Modeling and Optimal Control: A Case Study in Power Plant Start-Up”, International Federation of Automatic Control, Milan, 28 August-2 September, 2011.

[30] F. Belkhir, D. Kraus Cabo, F. Feigner, G. Frey, "Optimal Startup Control of a Steam Power Plant Using the JModelica Platform", $8^{\text {th }}$ Vienna International Conference on Mathematical Modelling, Wien, 18-20 February, 2015.

[31] F. Casella, E. Casati, P. Colonna, "Optimal Operation of Solar Tower Plants with Thermal Storage for System Design, International Federation of Automatic Control, Cape Town, South Africa, 24-29 August 2014.

[32] E. Casati, F. Casella, P. Colonna, "Design of CSP plants with optimally operated thermal storage", Solar Energy, 116, p. 371-387, 2015.

[33] S.Barsali, R.Giglioli, M.Giuntoli, G.Lutzemberger, D.Poli, “Control Strategies and Real Time Operation of Storage Systems Integrated with MV Photovoltaic Plants", 15th IEEE International Conference on Environment and Electrical Engineering (EEEIC), Rome, 10-13 June 2015.

[34] H.K.Yadav, Y.Pal, M.M. Tripathi, "Photovoltaic Power Forecasting Methods in Smart Power Grid", 2015 Annual IEEE India Conference (INDICON), 17-20 Dec. 2015, New Delhi, India.

[35] L.H. Saw, K. Somasundaram, Y. Ye, A.A.O. Tay, "Electro-thermal analysis of Lithium Iron Phosphate battery for electric vehicles”, Journal of Power Sources, 249, p. 231-238, 2014.

[36] J. Akesson, K.-E. Arzen, M. Gafvert et alii, Modeling and optimization with Optimica and JModelica.org - Languages and tools for solving large-scale dynamic optimization problems, Computers and Chemical Engineering, 34, p. 1737-1749, 2010.

[37] V. Ruge, W. Braun, B. Bachmann, A. Walther und K. Kulshreshtha, "Efficient Implementation of Collocation Methods for Optimization using OpenModelica and ADOL-C", $10^{\text {th }}$ International Modelica Conference, Sweden, 2014.

[38] A. Wächter und L. Biegler, "On the implementation of an interior-point filter line-search algorithm for large-scale nonlinear programming”, Math. Program, p. 25-57, 2006. 
[39] Winston battery official site, http://en.winston-battery.com/

[40] M. Ceraolo, G. Lutzemberger, D. Poli: “Aging evaluation of high power lithium cells subjected to micro-cycles”, Journal of Energy Storage, vol. 6, pages 116-124, 2016.

[41] Kokam Battery official site, http://www.kokam.com/cell

[42] Roland Berger, "Integrated Fuels and Vehicles Roadmap to 2030 and beyond", Roland Berger GmbH, 2016.

[43] C. McKerracher, S. Knupfer et alii, “An integrated perspective on the future of mobility”, McKinsey \& Company and Bloomberg New Energy Finance, 2016. 